\title{
DECIFRA-ME OU EU TE DEVORO! - OS FUNDAMENTOS SOCIOECONÔMICO-CULTURAIS DO MODO DE PRODUÇÃO CAPITALISTA E SUAS IMPLICAÇÕES NA HISTÓRIA DA EDUCAÇÃO E NO TRABALHO EDUCATIVO
}

\author{
Antonio Carlos Souza ${ }^{1}$ \\ César Aparecido Nunes ${ }^{2}$
}

Resumo: Este trabalho pretende discutir os fundamentos filosóficos e políticos da educação, a partir da perspectiva materialista dialético-histórica, como visão de mundo, como método de análise e como práxis. Vivemos numa situação histórica paradoxal em relação às condições socioeconômico-culturais: de um lado, o discurso de que estamos no melhor dos mundos possiveis, de constante progresso técnicocientífico e, de outro lado, a realidade de exploração da maioria dos seres humanos. Nosso objetivo é o de apresentar uma reflexão no sentido de desafiar os discursos e práticas e sua defesa do estado atual de coisas, que tem como fundamento o liberalismo político e o modo de produção capitalista, especificamente a questão da alienação e da ideologia e suas implicações na educação. Daí partirmos de uma reflexão-ação sobre as circunstâncias concretas, inseparável de uma reflexão-ação sobre as consciências, pois entendemos que a educação é uma atividade de interpretação-compreensão, assim como de intervenção-ação no mundo das relações concretas e contraditórias. Propomos o reconhecimento da atualidade do materialismo dialético-histórico e de sua potencialidade científica, histórica, filosófica e politica, como possibilidade de construção do homem omnilateral, capaz de ter consciência do real e de práxis interventiva e transformadora, na superação e abolição de toda forma de educação puramente operacional, técnica, instrumental, exploratória e mercantilista. É preciso pensar uma "educação para além do capital", que não se submeta ou se adapte aos interesses do capital, do "mercado de trabalho". Nosso objetivo é discutir a possibilidade e a necessidade objetiva da construção da sociedade e do homem politicamente emancipados.

Palavras-Chave: Educação; Práxis pedagógica; Filosofia.

\footnotetext{
${ }^{1}$ Doutor em Educação. Professor do Colegiado de Filosofia. Centro de Ciências Humanas e da

Educação, Campus Jacarezinho, Universidade Estadual do Norte do Paraná (UENP). E-mail: acsouza@uenp.edu.br

${ }^{2}$ Prof. César Nunes. Doutor em Filosofia e Educação. Livre-docente em Ética e Educação. Professor Titular na área de Filosofia e Educação da FE/UNICAMP.

E-mail: cnunes@unicamp.br
} 
Souza, A.C.; Nunes, C.A.

\section{DECIFER ME OR I WILL DEVOUR YOU! - THE SOCIOECONOMIC-CULTURAL FOUNDATIONS OF THE CAPITALIST PRODUCTION MODE AND ITS IMPLICATIONS IN THE HISTORY OF EDUCATION AND EDUCATIONAL WORK.}

This work intends to discuss the philosophical and political foundations of education, from the dialectical-historical materialist perspective, as a worldview, method of analysis and praxis. We live in a paradoxical historical situation in relation to socioeconomic and cultural conditions: on the one hand, the discourse that we are in the best of possible worlds, of constant technical and scientific progress and, on the other hand, the reality of exploration of the clear majority of human beings. Our objective is to present a reflection to challenge the discourses and practices and their defense of the current state of things, which is based on political liberalism and the capitalist mode of production, specifically the question of alienation and ideology and its implications on education. Hence, we start from an reflection-action on the concrete circumstances, inseparable from a reflection-action on the consciences, since we understand that education is an activity of interpretation-understanding, as well as intervention-action in the world of concrete and contradictory relations. We propose the recognition of the actuality of dialectical-historical materialism and its scientific, historical, philosophical and political potentiality as a possibility of construction of the unilateral man, capable of being aware of the real and of an interventionist and transforming praxis, in overcoming and abolishing all forms of purely operational, technical, instrumental, exploratory and mercantilist education. It is necessary to think of an "education beyond capital" that does not submit or adapt to the interests of the capital, of the "labor market". Our aim is to discuss the possibility and objective necessity of the construction of politically emancipated society and man.

Keywords: Education; Pedagogical praxis; Philosophy.

\section{¡DESCIFRAME O TE DEVORO! - LOS FUNDAMENTOS SOCIOECONÓMICO- CULTURALES DEL MODO DE PRODUCCIÓN CAPITALISTA Y SUS IMPLICACIONES EN LA HISTORIA DE LA EDUCACIÓN Y EL TRABAJO EDUCATIVO.}

Este trabajo pretende discutir los fundamentos filosóficos y politicos de la educación, desde la perspectiva materialista dialéctico-histórica, como visión de mundo, método de análisis y praxis. Vivimos en una situación histórica paradójica en relación con las condiciones socioeconómicoculturales: por un lado, el discurso de que estamos en el mejor de los mundos posibles, de constante progreso técnico-científico y, por otro lado, la realidad de explotación de la mayoría de los seres humanos. Nuestro objetivo es el de presentar una reflexión en el sentido de desafiar los discursos y prácticas y su defensa del estado actual de cosas, que tiene como fundamento el liberalismo político y el modo de producción capitalista, específicamente la cuestión de la alienación y de la ideología y sus implicaciones en la educación. De ahí partimos de una reflexión-acción sobre las circunstancias concretas, inseparable de una reflexión-acción sobre las conciencias, pues entendemos que la educación es una actividad de interpretación-comprensión, así como de intervención-acción en el mundo de las relaciones concretas y contradictorias. Proponemos el reconocimiento de la actualidad del materialismo dialéctico-histórico y de su potencialidad científica, histórica, filosófica y política, como posibilidad de construcción del hombre unilateral, capaz de tener conciencia de lo real y de la praxis intervencionista y transformadora, en la superación y abolición de toda forma de educación puramente operacional, técnica, instrumental, exploratoria y mercantilista. Es necesario pensar una "educación más allá del capital", que no se someta o se adapte a los intereses del capital, del "mercado de trabajo". Nuestro objetivo es discutir la posibilidad y la necesidad objetiva de la construcción de la sociedad y del hombre políticamente emancipados.

Palabras clave: Educación; Praxis pedagógica; Filosofia. 
Souza, A.C.; Nunes, C.A.

\section{Introdução}

Nem é necessário explicitar a metáfora que encabeça o título desse ensaio reflexivo: o enigma da Esfinge permanece sobre nossas cabeças, numa alegoria que envolve a ontologia e a politica, com um veredito inexorável. O tempo que vivemos pode ser entendido como a expressão da Esfinge, o rosto humano sinaliza que vivemos tempos de "humanização e ciência", mas o corpo de leão e as garras da águia, num zooantropomorfismo desleal, representam que nossos tempos são mais selvagens que os atributos do leão e mais traiçoeiros do que as características da Águia. Somos convocados a decifrar a Esfinge do capital e de seus tentáculos, em nossa conjuntura. O contrário pode representar nossa aniquilação ontológica e política.

Este trabalho tem como objeto de discussão a História da Educação e do processo educativo dentro dos marcos e fundamentos socioeconômicoculturais do liberalismo e do modo de produção capitalista. Para tanto, o procedimento investigativo parte da perspectiva materialista dialético-histórica, fundada no pensamento de Karl Marx e Friedrich Engels, como visão de mundo, com método de análise e como práxis interventiva, como uma forma de fazer e escrever a História da Educação e da Pedagogia. Entendemos que o referido procedimento epistemológico apresenta a concepção de mundo, sob a forma da trama de relações socioeconômico-culturais em suas contradições e conflitos históricos. Também o referido procedimento tem a pretensão de buscar a compreensão da realidade de maneira radical (indo à raiz da questão), rigorosa (nos procedimentos de investigação e apresentação da pesquisa) e de conjunto (levando em consideração o contexto socioeconômico-cultural) do problema investigado e discutido. E, por fim, este procedimento tem como fundamento a práxis, ou seja, a relação da teoria e prática, da reflexão-ação, como busca de compreensão, intervenção e transformação do estado atual de coisas, propiciando, assim, a perspectiva de novas sinteses no plano do conhecimento e da construção da realidade histórica.

É neste sentido que pretendemos investigar a História da Educação e a prática educativa e contribuir para a compreensão da realidade concreta dos trabalhadores da educação, como está e o porquê de sua situação atual e apresentar algumas possibilidades de superação. Entendemos que a educação 
Souza, A.C.; Nunes, C.A.

é uma atividade de interpretação-compreensão, assim como de intervençãoação no mundo das relações concretas e contraditórias. A relação entre conhecimento e ação é intrínseca tanto à teoria quanto à prática humana, de maneira específica no mundo da educação.

Partimos da hipótese que vivemos, como educadores, numa situação histórica paradoxal em relação às condições socioeconômico-culturais na produção de nossa existência material e do nosso trabalho educativo: de um lado, o discurso de que estamos no melhor dos mundos possíveis, num tempo de desenvolvimento e de ilimitado progresso técnico-científico e, de outro lado, a realidade de exploração, de precarização nos processos de trabalho e do processo educativo. Tal realidade tem seus impactos no processo formativo, na prática docente e no modo de produzir a História da Educação. De um lado vimos ser elencados identidades alienantes de nossa época e de nossa realidade, definida por alguns como "era do conhecimento", ou ainda a "era do ócio criativo", para outros a "sociedade informática" e tantos adjetivos otimistas e abstratos, além de enganosos e contraditórios.

Daí que algumas questões a serem discutidas são fundamentais, tais como a alienação, a ideologia, a mercantilização da educação, a precarização do trabalho. Esperamos que esta discussão possa contribuir na produção de consciência social, na produção de novos conhecimentos sobre a estrutura e dinâmica da sociedade atual e apresentar uma possibilidade epistemológica e política como subsídio teórico na formação dos educadores, com sujeitos e construtores da História da Educação e de sua prática educativa, social e política. O tempo que vivemos aproxima-se mais da sociedade do desemprego, da economia da exploração e do subemprego, do refluxo dos direitos sociais e políticos e do acintoso avanço das teorias e práticas do capital sobre todas as esferas da vida.

\section{Os fundamentos filosóficos e politicos da educação na perspectiva dialético-histórica}

O ponto de partida de nossa reflexão é a consideração que a educação é mediadora das práticas socioeconômico-culturais humanas no sentido de compreensão, intervenção e transformação dos próprios sujeitos, dentro do 
Souza, A.C.; Nunes, C.A.

movimento histórico. Daí que, tanto a história individual ou social, na sua concretude, é uma construção carregada de contradições e enfrentamentos antagônicos, e não um ideal que se utiliza a modo de contraste para ressaltar, ainda que isso seja necessário, a situação desumanizadora dos indivíduos concretos na sociedade atual e nem é o produto de sonhos utópicos sobre uma sociedade imaginariamente construida.

Neste sentido, para buscar compreender esta dinâmica da história, e especificamente sua dimensão educativa, nos aproximamos da Filosofia, fundamentada no materialismo dialético-histórico como uma reflexão "crítica, radical e de conjunto" (SAVIANI, 2002, p. 150), que propicia ao ser social a condição de conhecer, ter ciência do real e de, portanto, orientar os rumos da história individual e social, de intervir e transformar o mundo de maneira livre, consciente e criativa.

E, como a história é a ação dos homens na sua concretude socioeconômicocultural, não há outro caminho a seguir a não ser a busca da compreensão dos determinantes da lógica do modo de produção capitalista, da condição efetiva da classe trabalhadora, da sua consciência de classe e missão histórica de autoemancipação e emancipação humana universal. Daí que o processo analítico trata de um contraste não entre o real e o ideal, mas entre um passado e um presente históricos, fundamentos para um futuro igualmente histórico.

É nesta perspectiva que apresentamos algumas reflexões que envolvem a Filosofia e a Educação e sua potencialidade histórica. Partimos, assim, do materialismo dialético-histórico, a partir do pensamento de Karl Marx e Friedrich Engels, sua visão de história, de educação, do homem como ser de práxis, e sua potencialidade e necessidade histórica de conhecimento da lógica interna e das mazelas históricas do modo de produção capitalista.

O pensamento filosófico e educativo de Marx e Engels apresenta, assim, uma potencialidade crítica e sensibilizatória ao fazer uma análise crítica do modo de produção capitalista, e propõe como desafio histórico a sua superação. Mas este intento não segue um determinismo do curso dos acontecimentos, de maneira mecânica, idealista, mas segue a história como atividade dos homens que buscam seus fins. Neste sentido, para a realização histórica é necessário a produção das condições histórico-estruturais, como de mediações específicas, de ações concretas, para que tal transformação possa ser efetivamente realizada. Defendemos a tese da possibilidade da construção de uma nova história a partir da educação omnilateral da classe trabalhadora. 
Souza, A.C.; Nunes, C.A.

A questão educacional em Marx tem como primeiro pressuposto as condições materiais efetivas historicamente determinadas, das suas condições reais de existência, ou seja, de caráter socioeconômico-cultural. Por isso, os fundamentos da educação, nesta perspectiva, partem da concretude da vida real, de fatos humanos de maneira objetiva, racional.

Não partimos do que os homens dizem, imaginam e representam, tampouco do que eles são nas palavras, no pensamento, na imaginação e na representação dos outros, para depois se chegar aos homens de carne e osso; mas partimos dos homens em sua atividade real, é a partir de se processo de vida real que representamos também o desenvolvimento dos reflexos e das repercussões ideológicas desse processo real [...]. São os homens que produzem suas representações, suas ideias, etc., mas os homens reais, atuantes, tais como são condicionados por um determinado desenvolvimento de suas forças produtivas e das relações que a elas correspondem [...]. A consciência nunca pode ser mais que o ser consciente; e o ser dos homens é o seu processo de vida real [...] Não é a consciência que determina a vida, mas sim a vida que determina a consciência (MARX; ENGELS, 2002, p. 19-20).

No modo de produção capitalista, a "consciência", as "representações" são determinadas pela exploração do trabalho, pela propriedade privada dos meios de produção. Esta estrutura de sociedade produz a exploração, tanto da natureza quanto social, praticada por uma classe dominante, que se utiliza de representações e formas teóricas para justificar seus interesses de dominação, de manutenção do status quo. É e nesta dinâmica que está inserida a educação e sua história que, de um lado reproduz as condições vigentes, e de outro lado é um espaço de crítica aos modelos educacionais dominantes e possibilidade propositiva, no sentido de pensar e propor novas formas de ações transformadoras das condições materiais de existência e das relações socioeconômico-culturais.

Nas sociedades de classes, a educação e seus fundamentos diferem segundo as classes, porque "os pensamentos da classe dominante são também, em todas as épocas, os pensamentos dominantes", pois "a classe que é o poder material dominante numa determinada sociedade é também o poder espiritual dominante" ou ainda mais, "a classe que dispõe dos meios de produção material dispõe também dos meios de produção intelectual" (MARX; 
Souza, A.C.; Nunes, C.A.

ENGELS, 2002, p. 48). Por isso, no modo de produção capitalista, dividida em classes antagônicas, não há possibilidade de uma educação universal. Só é possivel um ser explorado defendendo um mesmo princípio daquele que o explora por uma imposição ideológica que camufla as reais condições de vida de ambos.

Assim, para que o principio e a prática individualista de relações entre os homens sejam superados pelo princípio: "Dê cada um segundo suas capacidades, a cada um segundo suas necessidades" (MARX, 2012, p. 32) é necessário um efetivo movimento de crítica, resistência, desmascaramento e superação dos imperativos da competição, da acumulação, da maximização dos lucros que regem não apenas todas as transações econômicas, mas as relações sociais em específicas do modo de produção capitalista. Tal modo de produção, apesar de se apresentar como uma teoria e prática emancipatórias, não eliminou a exploração do homem pelo homem. Não fez mais que modificar as formas da exploração, pois está fundado nela: "Em uma palavra, em lugar da exploração dissimulada por ilusões religiosas e politicas, a burguesia colocou uma exploração aberta, direta, despudorada e brutal" (MARX; ENGELS, 2010, p. 42).

A educação, na perspectiva materialista dialético-histórica, na sua análise crítica da totalidade das ações humanas, procura compreender o movimento que se apresenta como real proposta de criação de novas relações humanas, no sentido de propiciar aos homens, mediante reflexão e ação, a superação da exploração, do estado atual das coisas. Tal domínio só se realizará com a substituição do modo de produção capitalista por uma nova forma de associação, pois "é somente na comunidade que o indivíduo possui os meios de desenvolver suas faculdades em todos os sentidos; é somente na comunidade que a liberdade pessoal é possivel” (MARX; ENGELS, 2002, p. 92). Neste sentido, para Lênin, a educação consiste em identificar-se com a classe trabalhadora em sua organização e luta contra a classe dominante.

Para vencer a resistência dessas classes só há um meio: encontrar na própria sociedade que nos rodeia, educar e organizar para a luta, os elementos que possam - e, pela sai situação social, devam - formar a força capaz de varrer o velho e criar o novo (LÉNIN, 1984, p. 95). 
Souza, A.C.; Nunes, C.A.

As categorias fundamentais desta educação expressam a vinculação entre o indivíduo e a sociedade, a forma na qual aquele se integra e se realiza aos interesses sociais, coletivos. Tais fundamentos são expressões da prática social da classe trabalhadora, servindo, assim, de força motriz para serem concretizados ao longo do processo histórico, pois, como diz Makarenko (apud SHISKHIN, 1966, p. 63): “Nossa conduta se deve medir unicamente pelos interesses da coletividade e de cada um de seus membros".

Por isso, a finalidade da educação, nesta perspectiva, é investigar as práticas humanas, de maneira científica, racional, imanente, propositiva, de análise do estado atual de coisas, no sentido de buscar apreender a realidade social humana, como condição necessária de sua interferência e transformação. Por isso, o curso que tomarão os acontecimentos e o desenvolvimento da sociedade depende, em grande medida, das práticas educativas da classe trabalhadora, como diz Schaff (2001, p. 154): "O futuro é obra do homem. No cenário atual vemos o homo autocreator, o homem criador do seu próprio destino e que esteve presente durante todo o desenvolvimento histórico".

Esta abordagem radical da educação, como mediadora das relações humanas, não permite a idealização ou o caráter redentor, de previsibilidade fatalista para a história humana. Mas, se a educação, nesta perspectiva, não tem caráter determinista, sua prática se apresenta com sentido de necessidade, possibilidade de superação do estado atual de coisas, de propiciar a consciência da necessidade ativa de compreensão do desenvolvimento histórico e da participação interventiva e transformadora.

A humanidade só enfrenta as tarefas que pode resolver, pois, se se considera mais atentamente, se chegará à conclusão que a própria tarefa só aparece onde as condições materiais de sua solução já existem, ou, pelo menos, são captadas no processo de seu devir (MARX, 2000, p. 52).

A finalidade última é a emancipação humana, isto é, a construção de uma realidade especificamente humana, que não nascerá naturalmente e nem somente pelo esgotamento das forças capitalistas, mas pelo enfrentamento, 
Souza, A.C.; Nunes, C.A.

protesto, indignação, denúncia e ruptura com toda forma de alienação, de “reificação", de exploração do homem pelo homem, da ordem estabelecida, pois a história em si nada é senão a atividade dos homens que buscam seus fins e, o fim da educação, nesta perspectiva, é propiciar a todos os individuos humanos igual aspiração à emancipação, uma mesma pretensão de satisfazer suas necessidades humanas ou como diz Saviani (2002, p. 48): “Agir de modo intencional significa agir em função de objetivos previamente definidos".

Por isso, consideramos que tratar da educação, nesta perspectiva, é tão dificil quanto querer negar nela tal dimensão, pois compreendemos que nenhuma afirmação sobre a educação poderá ser considerada concluída. A educação se prova na ação, daí só podermos falar de educação mediante a ação efetiva dos seres humanos, em constante movimento, nas suas determinações materiais, históricas. Daí ser a educação um espaço de prática e reflexão crítica e radical no sentido de analisar os diversos movimentos históricos, suas contradições e conflitos, assim como suas efetivas e possíveis transformações, como ação do homem sobre as circunstâncias históricas.

A importância e a dimensão educativa são entendidas, assim, no sentido amplo, como processo vital de existência humana, isto é, aquilo que caracteriza a sua especificidade de ser social, a saber, a capacidade de conhecer, de ter ciência do real e de, portanto, intervir e transformá-lo na sua prática social. A apropriação de conhecimento é processo que reflete as condições materiais históricas e os interesses e valores sociais. Educar, assim, significa "garantir ao ser humano a possibilidade de interferir e, porque não, orientar os rumos de sua história individual e coletiva" (GOERGEN, 2001, p. 36).

O direcionamento da educação dentro dos determinantes históricos do modo de produção capitalista, que conduz a educação a uma mera qualificação técnica ou profissionalizante, marcadas pela lógica da competição, do acúmulo material e do sucesso mercantil, só pode ser transformado e superado mediante uma educação revolucionária, ou seja, com referenciais e práticas revolucionárias. Daí a articulação entre teoria e prática.

Para que a teoria saia do estado propriamente teórico e se converta em verdade prática é necessário que ela seja assimilada 
Souza, A.C.; Nunes, C.A.

por contingentes cada vez mais amplos de sujeitos sociais, emergindo como agentes efetivos da prática histórica. E isso pressupõe um trabalho educativo sem o qual resultará impossivel a mobilização da população para a realização das transformações necessárias, o que põe na ordem do dia a problemática desenvolvida pela filosofia dialética da educação com base na filosofia da práxis (SAVIANI, 1996, p. 183).

Portanto, a crítica ao modo de produção capitalista requer, para sua superação, uma efetiva proposta pedagógica interventiva e transformadora, um compromisso político e social dos educadores, dos educandos, da escola. É aqui que entra a dimensão política da educação, isto é, de não ajustamento, de não adaptação ao modo de produção capitalista, mas de ser uma mediação na formação de uma racionalidade consciente, interventiva, de fortalecer a resistência no desenvolvimento do processo social, nas várias dimensões humanas, especialmente a política, que significa agir sobre o mundo e compreender essa ação.

Quando afirmo que a educação é sempre um ato político, quero
como isso frisar que a educação cumpre sempre uma função
politica. Mas é preciso não identificar essa função política com
outra função que a educação cumpre que é a técnica. Estas
funções não se identificam, elas se distinguem. Mas, embora
distinguiveis, são inseparáveis, ou seja: a função técnica é
sempre subsumida por uma função politica (SAVIANI, 2002, p.
212).

Neste sentido, a educação se constitui numa atitude politica consciente, coerente com os principios da emancipação humana. Por isso, a necessidade de uma Filosofia da Educação como sua missão de ser "uma reflexão (radical, rigorosa e de conjunto) sobre os problemas que a realidade educacional apresenta" ou "produzir cidadania, consciência histórica, responsabilidade moral, elevação ética, participação política e sensibilização estética nas gerações presentes e futuras" (NUNES, 2003, p. 38-39).

E é neste sentido que a educação não pode ser compreendida à margem da história, pois ela é uma reflexão-ação dos problemas postos pelo desenvolvimento histórico, nos determinantes das relações do modo de produção capitalista. Desta forma, não é possivel separar a educação dos determinantes socioeconômico-culturais, pois ela não é um processo neutro, 
Souza, A.C.; Nunes, C.A.

mas inserida no movimento histórico, que a condiciona, mas também é condicionado por ela.

O trabalho educativo é o ato de produzir, direta e intencionalmente, em cada indivíduo singular, a humanidade que é produzida histórica e coletivamente pelo conjunto dos homens. Assim, o objeto da educação diz respeito, de um lado, à identificação dos elementos culturais que precisam ser assimilados pelos individuos da espécie humana para que estes se tornem humanos e, de outro lado e concomitantemente, à descoberta das formas mais adequadas para atingir esse objetivo (SAVIANI, 1991, p. 21).

Neste sentido, a educação cumpre a missão de uma contundente crítica das concepções e práticas educacionais atreladas à lógica do capital, que tem no individualismo, no lucro, na mercantilização, na competição e exploração do trabalho seus fundamentos e práticas. A educação capitalista não vai além da reprodução, legitimação e manutenção da ordem dominante vigente, incapaz de transcender os limites do capital. É neste contexto que surge a necessidade de pensar uma "educação para além do capital", como diz Mészáros (2005).

Porém, mesmo diante da força do capital, pensar uma alternativa educacional que seja formulada do ponto de vista da emancipação humana é um desafio possivel, pelo fato do modo de produção capitalista, mesmo com toda sua força condicionante, ser limitado em relação à sua imposição sobre a produção das ideias e do conjunto das praticas e aspirações humanas. As ideias não são impostas e aceitas automaticamente; por isso, as ideias capitalistas como construções socioeconômico-culturais históricas não são naturais, nem eternamente necessárias. Quer dizer, é no interior do próprio desenvolvimento do modo de produção capitalista que, de um lado há a manutenção da ordem vigente e, de outro lado, nascem as práticas superadoras e construtoras de uma nova realidade.

Esta necessidade de compreensão do conjunto das ações humanas é defendida por Marx nos seus escritos quando, por exemplo, denuncia a educação burguesa como despolitização dos trabalhadores, considerando "os trabalhadores como mercadoria" e "com a valorização do mundo das coisas, aumenta em proporção direta a desvalorização do mundo dos homens" (MARX, 
Souza, A.C.; Nunes, C.A.

2004, p. 80). Neste sentido, quanto mais a educação é condicionada ao mercado capitalista menos hominiza-se a si mesmo e menos humaniza a natureza. O capital fica estabelecido como o fundamento da produção, da educação e da própria vida humana.

A produção produz o homem não somente como uma mercadoria, a mercadoria humana, o homem na determinação da mercadoria; ela o produz, nesta determinação respectiva, precisamente como um ser desumanizado tanto espiritual quando corporalmente (MARX, 2004, p. 92-93).

Porém, como diz Engels, "a miséria não só ensina o homem a rezar: também ensina a pensar e atuar" (MARX; ENGELS, 1983, p. 80). Por isso, é fundamental tratar a questão da educação não desvinculada do conjunto da produção social da vida humana, pois pensar a transformação das condições objetivas nas quais o modo de produção capitalista se impõe sobre a humanidade significa compreender as suas contradições. Falar de educação, nesta perspectiva, exige, portanto, uma atitude analitica crítica de toda teoria e prática pautada no adestramento, na doutrinação, subordinação, servilismo, dependência, que transforma a classe trabalhadora em mercadoria, coisa, em ser alienado e propor alternativas de superação de tal condição. Marx, em uma das mais contundentes criticas sobre a forma capitalista de tratar o trabalhador, diz:

Deforma (aleija) o trabalhador convertendo-o numa anomalia, levando-o artificialmente a desenvolver uma habilidade parcial à custa da repressão de um mundo de instintos [...] o indivíduo é mutilado e transformado no aparelho automático de um trabalho parcial [...] sua força individual do trabalho não funciona se não estiver vendida ao capital [...] a deformação física e espiritual é inseparável mesmo da divisão do trabalho em geral na sociedade [...] Subdividir um homem significa executá-lo, se merece a pena de morte, e se não a merece, assassiná-lo [...] A subdivisão do trabalho é o assassino de um povo (MARX, 1988, p. 270-272).

O processo de produção de uma educação transformadora passa, antes de tudo, pelo debate entre uma teoria reflexivo-analítica, de esclarecimento racional, e uma prática consciente, possivel, propositiva, aberta, possibilitando à classe trabalhadora ser sujeito capaz de compreender, se posicionar e intervir nos processos de produção da vida e da sociedade para, como diz 
Souza, A.C.; Nunes, C.A.

Engels, "produzir homens plenamente desenvolvidos [...] não deixar enfraquecer todas as forças físicas e morais [...] e o embrutecimento tanto sobre o organismo como sobre as faculdades mentais dos trabalhadores" (MARX; ENGELS, 1983, p. 24-25).

Nesse momento de nossa caminhada histórica reconhecemos que, a Idade Moderna, inaugurada a partir do século XVI, constitui uma nova realidade política, capitaneada pela burguesia emergente, que anunciava a superação das forças produtivas medievais e revelava, no seu projeto politico, a suposta potencialidade da construção de um novo ideário ético político, jurídico e institucional. Nessa caminhada vitoriosa, a burguesia foi capaz de anunciar os valores fundamentais da sociedade moderna; a saber, a igualdade, a liberdade, a prosperidade, a fraternidade, a afirmação do homem, o antropocentrismo, a razão como soberana, o logos como capaz de iluminar o mundo, a experiência como coadjuvante da transformação material do universo, o racionalismo, o Estado, o primado das leis, a organização de uma nova ética e de uma nova sociedade. Foram essas bases ideológicas da sociedade moderna, do que entendemos por Esclarecimento ou Iluminismo, um vertiginoso movimento de renovação cultural e de rearranjo político e material ocorrido na Europa e depois em muitos outros estados, nações e sociedades.

Hoje, transcorridos cinco séculos dessa forma de organizar a vida material, centrada na propriedade privada dos meios de produção, na lógica da lucratividade e na exploração da natureza e seus recursos, vimos que a vivemos uma aporia histórica e política. Somente uma nova organização da economia e uma nova forma de ordenar a política, a partir dos trabalhadores e sua inalienável capacidade revolucionária, seremos capazes de mudar o mundo e suas feições.

Neste sentido, a educação é entendida dentro do processo de produção histórica, como um movimento dinâmico, contraditório, que está sendo construída a cada dia por indivíduos que estão vivendo seu momento histórico, como produtos e produtores das determinações históricas. Só assim é possivel acreditar, possibilitar e fazer acontecer concretamente as mudanças, as transformações, as “necessárias aspirações emancipadoras” (MÉSZÁROS, 2005, p. 59). 
Souza, A.C.; Nunes, C.A.

Assim, a classe trabalhadora, como classe revolucionária, é que pode reagir contra toda forma de exploração, de reprodução ou aceitação do já determinado. E sua teoria e prática, também no campo educacional, se choca com discursos e práticas petrificadas, resignadas, que insistem em manter suas maneiras de pensar, organizar o processo sócioeconômico-cultural.

O papel da educação é soberano, tanto para a elaboração de estratégias apropriadas e adequadas pra mudar as condições objetivas de reprodução, como para a automudança consciente dos indivíduos chamados a concretizar a criação de uma ordem social metabólica radicalmente diferente. $E$ isso que se quer dizer com a concebida 'sociedade de produtores livremente associados'. Portanto, não é surpreendente que na concepção marxista a "efetiva transcendência da auto-alienação do trabalho" seja caracterizada com uma tarefa inevitavelmente educacional (MÉSZÁROS, 2005, p. 65).

É por isso que, ao longo da nossa reflexão, além da constatação, da denúncia e da crítica a todas as formas de alienação, desumanização, reificação, fetichização, exploração humana, levadas a cabo de uma maneira radical pelo modo de produção capitalista, defendemos a possibilidade e necessidade histórica de ruptura, de superação de tal condição e de construção de novas relações entre o homem, a natureza e a sociedade, enfim a construção da nova sociedade. O papel da educação, orientado nesta perspectiva de superar e ir "para além do capital” é absolutamente crucial para esse propósito.

A educação para além do capital visa uma ordem social qualitativamente diferente. Agora não só é factivel lançar-se pelo caminho que nos conduz a essa ordem, como o é também necessário e urgente. Pois as incorrigiveis determinações destrutivas da ordem existente tornam imperativo contrapor aos irreconciliáveis antagonismos estruturais do sistema do capital uma alternativa concreta e sustentável para a regulação da reprodução metabólica social, se quisermos garantir as condições elementares da sobrevivência humana. O papel da educação, orientado pela única perspectiva positivamente viável de ir para além do capital, é absolutamente crucial a este propósito (MÉSZAROS, 2005, p. 71-72).

Enfim, insistimos mais uma vez naquilo que defendemos, ou seja, a emancipação humana e social só será possivel a partir da crítica radical, da 
Souza, A.C.; Nunes, C.A.

ruptura efetiva de todas as estruturas sociais, econômicas, politicas, culturais, educacionais desumanizantes e exploratórias, produzidas pelo modo de produção capitalista. Daí que, ter conhecimento do real é condição fundamental para lutar contra a exploração, a opressão, a dominação e a alienação, isto é, conhecer e demonstrar as contradições do capital. Esta é a tarefa fundamental da perspectiva educacional da classe trabalhadora.

\section{CONSIDERAÇÕES FINAIS}

A presente reflexão foi produzida com o intuito de expressar e propor um debate sobre a questão educacional a partir de algumas referências e leituras do pensamento social de Marx e Engels. Partimos da convicção que a construção de uma educação omnilateral faz parte do movimento dinâmico da história humana, nas suas contradições, construída a cada dia por individuos que estão vivendo seu próprio momento histórico. Só assim é possivel acreditar, possibilitar e fazer acontecer concretamente as mudanças, as transformações e realizar as aspirações humanas emancipadoras.

Neste sentido, entendemos a atualidade e potencialidade revolucionária do pensamento de Marx e Engels sobre a educação que tem como fundamento a discussão sobre a união, organização e educação da classe trabalhadora como condição necessária de enfrentamento de todos os discursos e práticas do modo de produção capitalista, que trata tanto a educação, assim como outras dimensões humanas fundamentais como objeto mercantilista, a serviço do capital. Assim, a educação, em Marx e Engels, além de desafiar e reagir a qualquer tentativa de limitar o trabalhador a um ser unilateral quer mostrar que cabe à classe trabalhadora a construção do seu destino e do destino da humanidade na sua concreticidade histórica, onde cada individuo possa exercer a totalidade de sua capacidade produtiva, se aproprie da totalidade dos bens produzidos universalmente, participe da totalidade do seu processo educacional e politico. 
Souza, A.C.; Nunes, C.A.

\section{REFERÊNCIAS}

ENGELS, F. Anti-Dühring. Rio de Janeiro: Paz e Terra, 1976.

GOERGEN, P. Pós-Modernidade, Ética e Educação. Campinas: Autores Associados, 2001.

LÉNIN, V. I. As três fontes e as três partes constitutivas do marxismo. Lisboa: Avante, 1984. (Obras Escolhidas 2).

MARX, K. O Capital. São Paulo: Nova Cultural, 1988.

2000. . Introdução à Crítica da Economia Politica. São Paulo: Nova Cultural, . Manuscritos Econômico-Filosóficos. São Paulo: Boitempo, 2004. . Critica do Programa de Gotha. São Paulo: Boitempo, 2012.

MARX, K.; ENGELS, F. Textos Sobre Educação e Ensino. São Paulo: Moraes, 1983.

A Ideologia Alemã. São Paulo: Martins Fontes, 2002.

Manifesto Comunista. São Paulo: Boitempo, 2010.

MÉSZÁROS, I. A Educação Para Além do Capital. São Paulo: Boitempo, 2005.

NUNES, C. Educar para a Emancipação. Florianópolis: Sophos, 2003.

SAVIANI, D. Filosofia da educação: crise da modernidade e o futuro da filosofia da práxis. In: FREITAS, M.C (Org.). A reivindicação do futuro: trabalho, educação, política na globalização do capitalismo. São Paulo: Cortez; Bragança Paulista: USF-IFAN, 1996.

. Educação: do Senso Comum à Consciência Filosófica. Campinas:

Autores Associados, 2002.

. Pedagogia Histórico- Crítica: primeiras aproximações. Campinas:

Autores Associados, 1991.

SCHAFF, A. A sociedade Informática. São Paulo: Brasiliense, 2001.

SHISKHIN, A. Ética. Buenos Aires: Cartago, 1966. 